\title{
UNIVERSITYOF BIRMINGHAM

\section{Relationship between Psychological and Biological Factors and Physical Activity and Exercise Behaviour in Filipino Students}

\author{
Polman, P; Pieter, W; Bercades, LT; Ntoumanis, Nikolaos
}

DOI:

10.1080/1612197X.2004.9671733

Citation for published version (Harvard):

Polman, P, Pieter, W, Bercades, LT \& Ntoumanis, N 2004, 'Relationship between Psychological and Biological Factors and Physical Activity and Exercise Behaviour in Filipino Students', International Journal of Sport and Exercise Psychology, vol. 2, pp. 81-97. https://doi.org/10.1080/1612197X.2004.9671733

Link to publication on Research at Birmingham portal

\section{General rights}

Unless a licence is specified above, all rights (including copyright and moral rights) in this document are retained by the authors and/or the copyright holders. The express permission of the copyright holder must be obtained for any use of this material other than for purposes permitted by law.

- Users may freely distribute the URL that is used to identify this publication.

- Users may download and/or print one copy of the publication from the University of Birmingham research portal for the purpose of private study or non-commercial research.

- User may use extracts from the document in line with the concept of 'fair dealing' under the Copyright, Designs and Patents Act 1988 (?)

- Users may not further distribute the material nor use it for the purposes of commercial gain.

Where a licence is displayed above, please note the terms and conditions of the licence govern your use of this document.

When citing, please reference the published version.

Take down policy

While the University of Birmingham exercises care and attention in making items available there are rare occasions when an item has been uploaded in error or has been deemed to be commercially or otherwise sensitive.

If you believe that this is the case for this document, please contact UBIRA@lists.bham.ac.uk providing details and we will remove access to the work immediately and investigate. 


\title{
Relationship Between Psychological and Biological Factors and Physical ACTivity and Exercise Behaviour in Filipino Students
}

\author{
Remco Polman', Willy Pieter², Luigi T. Bercades², and Nikos Ntoumanis ${ }^{3}$ \\ 'Leeds Metropolitan University, England. \\ ${ }^{2}$ University of Asia and the Pacific, Pasig City, Philippines. \\ ${ }^{3}$ University of Birmingham, England.
}

\begin{abstract}
The aim of the present study was threefold. Firstly, it investigated whether a general measure or specific measure of motivational orientation was better in describing the relationship between motivation and exercise behaviour. Secondly, it examined the relationship between the four most popular indirect methods of body composition assessment and physical activity and exercise patterns. Thirdly, the interaction between motivation and body composition on physical activity and exercise behaviour was explored in a sample of 275 Filipino male and female students. Males were found to have higher levels of exercise whereas females had higher levels of physical activity. Furthermore, general self-motivation together with body weight and percentage body fat were found to be the best predictor of exercise behaviour whereas the tension/pressure subscale of the 'Intrinsic Motivation Inventory' (IMI) was the best predictor of levels of physical activity. However, significant gender differences were observed. That is, for the males only self-motivation and for the females only body weight and BMl predicted exercise behaviour. Also, tension/pressure predicted physical activity levels for the females but not the males. No inverse relationship was found between the four body composition measures and exercise and physical activity behaviour. The results support the notion that the psychobiological approach might be particularly relevant for high intensity exercise situations but also highlights some important gender differences. Finally, the results of this study emphasise the need for more cross-cultural research.
\end{abstract}

Key words: body composition, exercise and physical activity patterns, motivation

Correspondence regarding this article should be addressed to: Dr Remco Polman, Leeds Metropolitan University, School of Leisure and Sports Studies, Beckett Park Campus, Fairfax Hall, Leeds LS6 3QS. Telephone: ++ 01132832600 extension 4702. E-mail: r.polman@lmu.ac.uk 
Remco Polman, Willy Pieter, Luigi T. Bercades, \& Nikos Ntoumanis

Only $10-15 \%$ of the population in industrialised countries exercises regularly and intensively enough to meet current guidelines for fitness and health benefits (Sallis \& Owen, 1999; US DHHS, 2000). The question of incorporating regular physical activity and exercise into people's lifestyles has, therefore, become an important field of study. Given the complexity of physical activity and exercise behaviour and the many factors that influence participation, to find a single attribute that would be capable of predicting physical activity or exercise adoption, adherence, and resumption would be unlikely (Garcia \& King, 1991). Motivation, however, has been shown to be a crucial personal factor that influences physical activity and exercise behaviour (Biddle, Fox, \& Boutcher, 2000). For example, motivation is important for initial adoption and subsequent adherence to medical as well as physical activity and exercise programs (Annesi, 2002; Dishman, 2001; Ryan, Frederick, Lepes, Rubio \& Sheldon, 1997). In this respect, it has been suggested that there might be a general personality trait of selfmotivation, "a non-specific tendency to persist in habitual behaviour regardless of extrinsic reinforcement and largely independent of situational influences" (Dishman \& Gettman, 1980, p. 297). Dishman and Ickes (1981) developed an inventory measuring this first-order personality trait. Research in the domain of exercise and physical activity has shown that the Self-Motivation Inventory (SMI) is indicative of compliance to physical activity and exercise programs, that is, increased levels of self-motivation reflecting lower attrition rates (Dishman \& Gettman, 1980; Dishman \& Ickes, 1981; Dishman, Ickes, \& Morgan, 1980; Heiby, Onorator, \& Sato, 1987; King et al., 1992; Robertson \& Mutrie, 1989; Wilcox \& Storandt, 1996). Participants with high levels of self-motivation are believed to have appropriate selfregulating skills, set appropriate goals, provide their own reinforcement (Berger, Pargman, \& Weinberg, 2002) and are able to maintain personal programs (Dishman \& Steinhardt, 1988). Self-motivation, therefore, would appear to be an important motivational factor that would not only be able to discriminate between adherence and dropout but also between people engaging in exercise at different levels of intensity, frequency, and duration (Biddle \& Mutrie, 2001; Steinhardt \& Young, 1992).

Another important distinction concerning motivation that has been successfully applied to the exercise domain is the self-determination approach (Chatzisarantis, Biddle, \& Meek, 1997; Deci \& Ryan, 1985; Ntoumanis, 2001). This theory postulates that any type of behaviour can be broadly characterised as being intrinsically motivated, extrinsically motivated, or amotivated. In the area of exercise, intrinsic motivation refers to activities in which individuals freely engage because they find them interesting and enjoyable. Three types of intrinsic motivation for exercise have been described based on the work by Vallerand and colleagues (Vallerand et al., 1992). These are intrinsic motivation to learn, to accomplish, and to experience stimulating sensations. These three types of intrinsic motivation are viewed as self-determined forms of motivation. In contrast, extrinsic motivation is evident when individuals perform an exercise activity because they value its associated outcomes (e.g., public praise, improved physique) more than the activity itself. Four types of extrinsic motivation for exercise have been described based on Deci and Ryan's (1985) conceptualisation. These are external regulation, introjected regulation, identified regulation, and integrated regulation. Whereas both intrinsic motivation and extrinsic motivation represent different degrees of volition, amotivation, the third type of behavioural regulation described by Deci and Ryan (1985), represents the absence of motivation. Amotivation is evident when one lacks the intention and willingness to engage in any exercise behaviour. Research in the area of exercise has shown that self-determined types of motivation

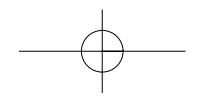


(intrinsic motivation) are more likely to be associated with positive, adaptive behavioural outcomes, compared to less self-determined types. For example, Biddle, Soos, and Chatzisarantis (1999) using a sample of over 700 Hungarian children aged 12-16 showed that physical activity intentions were positively predicted by intrinsic motivation as well as identified regulation. Different types of motivation have also been related to actual behaviour. For example, Ryan and colleagues (Ryan et al., 1997) using two independent samples of university exercise participants showed that long-term adherence to exercise was predicted by intrinsic motives for exercise (i.e., enjoyment and competence), but not by extrinsic motives (i.e., fitness and appearance). Moreover, competence and interest/enjoyment motives have been positively correlated with number of hours of weekly participation in physical activity, whereas bodyrelated motivation has been negatively correlated with number of hours per week of participation, length of workouts, and perceived future participation (Frederick \& Ryan, 1993). Intrinsically motivated forms of behaviour regulation, in this respect, are said to be particularly desirable for adherence to physical activity and exercise whereas extrinsic motives are important for exercise adoption (Ryan et al., 1997). One way of assessing levels of intrinsic motivation is by means of the Intrinsic Motivation Inventory (IMI) (McAuley, Duncan, \& Tammen, 1989). The IMI measures four aspects of intrinsic motivation (interest/enjoyment; perceived competence; effort/importance; tension/pressure) which are akin to the three types of intrinsic motivation identified by Vallerand et al. (1992).

Whereas the SMI is a general measure of persistence towards goals, not specific to exercise and physical activity, the IMI has been developed to specifically measure participants' levels of intrinsic motivation towards exercise and physical activity. The first aim of the present study was to investigate whether a general measure or specific measure of motivational orientation was better in describing the relationship between motivation and exercise behaviour in a population of Filipino students.

In addition to motivational issues it has been suggested that biological factors might also be important to adoption and adherence to physical activity and exercise participation (Dishman et al., 1980). Wilfley and Brownell (1994) reported barriers among obese individuals that may impede them from participating in physical activity or exercise, including previous negative experiences (teasing, inferior performance, embarrassment, and feelings of inadequacy) as well as the physical burden of their excess weight, predisposing obese participants to experience physical activity and exercise as more effortful and causing more discomfort. High levels of body fat and/or excessive body weight at the start of a physical activity or exercise program have been shown to be predictive of later dropout (Dishman \& Gettman, 1980; Dishman \& Ickes, 1981; Massie \& Sheppard, 1971; Robertson \& Mutrie, 1989). Furthermore, cross-sectional, population-based studies have consistently shown that body weight (Ballor \& Keesey, 1991), percentage body fat (Duncan, Gordon, \& Scott, 1991), waist-to-hip ratio (WHR) (Selby, Newman, \& Quesenberry, 1990; Siedell, Bjorntorp, \& Sjostrom, 1989) and body mass index (BMI) (U.S. Department of Health and Human Services, 1996) have been inversely correlated with self-reported physical activity and exercise behaviour. From the current literature it is not clear which body composition measure would be most useful in predicting exercise behaviour. Rather than selecting one technique in favour of another in the present study the opportunity was taken to compare the four most popular indirect methods of body composition assessment (body weight, BMI, WHR, body fat percentage) to physical activity and exercise behaviour. 
Remco Polman, Willy Pieter, Luigi T. Bercades, \& Nikos Ntoumanis

Finally, few studies have systematically explored the interaction between body composition and motivation on physical activity and exercise behaviours. Although the "psychobiological" approach (Dishman et al., 1980) has intuitive appeal the few studies that investigated the relationship between biological and psychological factors on physical activity and exercise behaviour have shown mixed results. Furthermore, the studies that have been conducted in this area have mainly focused on the relationship between self-motivation, body composition, and exercise behaviour. Dishman et al. (1980), for example, found that compared to dropouts, adherers are leaner, lighter, and more self-motivated. However, Ward and Morgan (1984) failed to replicate these findings. In their study, the psychobiological model successfully predicted adherence but failed to predict dropout. Biddle and Mutrie (2001) have recently suggested that the discriminating power of the psychobiological model might depend on the level of exercise intensity. They suggest that high-intensity activities would require high levels of self-motivation and favourable physiological factors such as low levels of body fat, whereas this might not be the case for habitual physical activity of an unstructured nature. Furthermore, Biddle and Mutrie (2001) suggest that self-motivation might be particularly important when few extrinsic motivators are in evidence. The third objective of the present study, therefore, was to investigate the relationship between self-motivation and intrinsic motivation and body composition on physical activity and exercise behaviour in a sample of Filipino students.

The aim of the present study was threefold. Firstly, it investigated whether a general measure or specific measure of intrinsic motivational orientation was better in describing the relationship between motivation and exercise and physical activity behaviour. Secondly, it examined the relationship between the four most popular indirect methods of body composition assessment and physical activity and exercise patterns. Thirdly, the interaction between motivation and body composition on physical activity and exercise behaviour was explored. Based on the current literature the present study predicted that exercise behaviour would be related to self-motivation and body composition measures, whereas physical activity patterns would not exhibit such a relationship. That is, participants with higher level of exercise would score higher on selfmotivation and would exhibit favourable body composition measures. Furthermore, it was hypothesised that high levels of physical activity and exercise participation would be correlated with higher levels of intrinsic motivation. This would be indexed by lower scores in tensionpressure (Ward \& Morgan, 1984) but higher scores in interest-enjoyment and competence (Frederick \& Ryan, 1993). It was also expected that there would be gender differences in motivational orientation as well as physical activity and exercise patterns. Women appear to be particularly prone to appearance and fitness-related orientations in comparison to males (Frederick \& Ryan, 1993; Silberstein, Striegel-Moore, Timko, \& Rodin, 1988; Tappe, Duda, \& Menges-Ehrnwald, 1990). These findings suggest that women are more extrinsically motivated than men and possibly less intrinsically motivated towards exercise participation than men. Also, younger age men tend to have higher exercise levels than females (Schoenborn, 1986). However, when physical activities are included in the determination of regular leisure time, this difference in activity levels between gender is reduced or disappears (Stephens, Jacobs, \& White, 1985). Thus males were predicted to exhibit higher levels of physical exercise whereas females would display higher levels of physical activity. Finally, it was expected that there would be an inverse relationship between selected body composition measurements and physical activity and exercise levels. That is, physically more active subjects would show lower body weight, BMI, WHR, and percentage body fat in comparison to less active subjects.

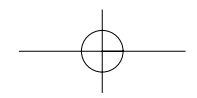




\section{METHOD}

\section{Participants}

The participants were 275 (112 males, 163 females) undergraduate students at the University of Asia and the Pacific, Manila, Philippines. This is a private University and the socio-economic background of the majority of students attending this University is middle to upper class. Age ranged from $16-28$ years with a mean age of 17.85 years (SD \pm 1.18 ). Ethical approval for the study was provided by the University and all participants signed an informed consent form at the start of the study.

\section{INSTRUMENTS}

It should be noted that most Filipinos are bilingual in Filipino and English. All students at the University have been educated in English at primary, secondary, and University level. Therefore, the instruments used were in the English language. Height was measured to the nearest $0.05 \mathrm{~cm}$ using a wall-mounted stadiometer. Participants' weight was assessed using a calibrated digital electronic scale. They were instructed to remove their shoes and to wear their normal gym class clothing. Measurements were to the nearest 0.01 kilogram. Based on height and weight participants BMI was calculated (body mass divided by stature squared). Waist and hip circumferences were measured using a dressmaker's tape. Waist circumference was taken at the horizontal level between the xiphisternum and the umbilicus that yielded the minimum measurement. Hip circumference was the horizontal level around the buttocks posteriorly that yielded the maximum measurement. If duplicate readings differed by more than $2 \mathrm{~cm}$, a third was taken. The average of the duplicates or the closest two of the three measurements was subsequently used to calculate the waist-hip circumference ratio. Slimguide skinfold calipers were used by competent examiners to assess skinfold thicknesses at the tricipital and subscapular sites. All measurements were taken on the right side of the body. Three measurements were taken at each site with the median being used as the score for analysis (note: the sites were marked using a pencil to ensure that all three readings were taken at the same location). If the first two readings were the same, a third was not taken. Percentage body fat was calculated using the formulas put forward for male and female Japanese adults (Tsunenari et al., 1993). The validity and reliability of skinfold measurements for calculating body fat percentage is dependent on technical skill, type of caliper, subject factors, and the prediction equation (Heyward \& Stolarczyk, 1996). It is a suitable method for large scale crosssectional investigations in which body fat percentage can be estimated with an accuracy of 34\% (Lohman, 1981).

The SMI (Dishman \& Ickes, 1981) is a 40-item questionnaire self-scored on a 5-point Likert scale ranging from "extremely uncharacteristic of me" to "extremely characteristic of me". Of the 40 items, 19 are positively and 21 negatively keyed. Possible scores range from 40-200. The SMI has yielded a high index of internal consistency $(r=0.91)$ as well as high test-retest reliability ( $r$ 's ranging from 0.86 to 0.92 ) in research on physical activity and exercise behaviour (Dishman \& Ickes, 1981; Dishman et al., 1980). The IMI items are specially written for easy adaptability to a variety of tasks and activities. The 18-item version of the IMI (McAuley et al., 1989), in this study, was modified to assess the participants general intrinsic motivation 
Remco Polman, Willy Pieter, Luigi T. Bercades, \& Nikos Ntoumanis

for the class/activity they were participating in. The instrument is scored on a 7-point Likert scale ranging from "strongly disagree" to "strongly agree" and has four subscales: interest/enjoyment; perceived competence; effort/importance; tension/pressure. Coefficient alphas obtained for these four dimensions have indicated satisfactory reliability in the physical activity and exercise domain (McAuley et al., 1989), however, its factorial validity has recently been questioned (Vallerand \& Fortier, 1998).

Finally, subjects were asked to rate their physical exercise and activity patterns. Energy expenditure of the subjects was quantified based on a self-administered questionnaire assessing each type of activity with the amount of time (in minutes/week) and intensity in units of METs (metabolic equivalents). Total energy costs were based on the activities incurred for a week using the FitKid Physical Activity Questionnaire, a modified inventory based on the one used in the Amsterdam Growth Study and the Paffenbarger Harvard Alumni Questionnaire (Montoye, Kemper, Saris, \& Washburn, 1996). Activities assessed the following categories: (a) Physical education, (b) extracurricular,(c) organised physical activity, (d) regular exercise, (e) general physical activity, and (f) household chores. Total energy expenditure as well as energy expenditure for exercise (a-d) and physical activity (e and f) were calculated. Although this method is fairly crude and has obvious limitations, it was felt the appropriate way for assessing physical activity and exercise patterns for the population under investigation.

\section{PROCEDURE}

All measurements were taken or administered at the start of a regular school semester to students who attended compulsory physical education classes. Body composition measurements were always taken first. Subjects were then instructed to complete the Intrinsic Motivation Inventory and Self-Motivation Inventory. Finally, subjects completed the FitKid Physical Activity Questionnaire to measure their levels of exercise and physical activity.

\section{STATISTICAL ANALYSIS}

For 226 (90 males, 136 females) out of the 275 participants a complete data set was available regarding their physical activity and exercise behaviour patterns. An independent t-test was used to establish gender differences in their exercise and physical activity behaviour and for differences in intrinsic motivation. Hierarchical, multiple linear regression models were used for the prediction of exercise and physical activity behaviour separately from the ordered entry of Self-motivation, followed by the four intrinsic motivation scales, followed by the four body composition measures, and finally gender was entered. Standardized regression ( $\beta$ ) coefficients described the independent contribution of each predictor to the total regression models. Due to the a priory prediction that males and females would differ in their levels of exercise and physical activity the hierarchical multiple regression was also run for the males and females independently. Finally, Pearson coefficient correlations were calculated between the body composition measurements and the physical activity, exercise, and total activity patterns for the males and females separately.

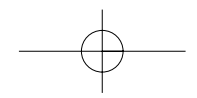




\section{RESULTS}

The internal consistency of the SMI and the four subscales of the IMI were first determined by coefficient alpha (Cronbach, 1951). Internal consistency was found to be adequate for the SMI and the IMI subscales: SMI $(\alpha=0.67)$; interest/enjoyment $(\alpha=0.78)$; perceived competence $(\alpha=0.75)$; effort/importance $(\alpha=0.79)$; tension/pressure $(\alpha=0.62)$. Table 1 provides an overview of the means and standard deviations for the dependent variables for the males and females separately. Males were found to have significantly higher levels of exercise than the females, $t(224)=6.09, p \leq 0.001$, whereas the females exhibited significantly higher levels of physical activity than the males, $t(224)=-2.02, p=0.045$. Finally, the independent $t$-test for total activity patterns (physical activity and exercise pooled together) also revealed a significant difference, $t(224)=4.96, p<0.001$, total activity patterns for males being significantly higher than that of the females.

Table 1

Means and standard deviation for the independent and dependent variables.

\begin{tabular}{lll} 
& Males $(N=90)$ & Females $(N=136)$ \\
\hline $\begin{array}{l}\text { Exercise levels } \\
\text { kcal/kg/week }\end{array}$ & $2506 \pm 1827$ & $1811 \pm 1217$ \\
$\begin{array}{l}\text { Physical activity levels } \\
\text { kcal/kg/week }\end{array}$ & $490 \pm 851$ & $735 \pm 913$ \\
$\begin{array}{l}\text { Total activity levels } \\
\text { kcal/kg/week }\end{array}$ & $2998 \pm 2005$ & $2546 \pm 1682$ \\
Self-motivation & $109.3 \pm 16.94$ & $109.5 \pm 16.15$ \\
Interest/enioyment & $4.99 \pm 0.70$ & $4.87 \pm 0.59$ \\
Perceived competence & $4.47 \pm 0.77$ & $4.39 \pm 0.66$ \\
Effort/importance & $4.87 \pm 0.63$ & $4.92 \pm 0.59$ \\
Tension/pressure & $3.72 \pm 0.82$ & $3.73 \pm 0.89$ \\
Body weight & $69.38 \pm 16.20$ & $50.00 \pm 7.96$ \\
WHR & $0.865 \pm 0.09$ & $0.800 \pm 0.11$ \\
BMl & $23.73 \pm 4.89$ & $20.47 \pm 3.05$ \\
Percentage fat & $22.38 \pm 8.27$ & $22.87 \pm 4.42$ \\
& &
\end{tabular}


Remco Polman, Willy Pieter, Luigi T. Bercades, \& Nikos Ntoumanis

No gender differences in intrinsic motivation were found (interest/enjoyment $t[273]=1.62$, $p=0.11$; perceived competence $t[273]=0.93, p=0.35$; effort/importance $t[273]=-0.33$, $p=0.74$; tension/pressure $+[273]=0.24, p=0.85)$. This does not support the a priory hypothesis that females would have lower levels of intrinsic motivation in comparison to males.

The hierarchical, multiple regression model for exercise showed that self-motivation, body weight, and percentage body fat significantly contributed to the prediction of levels of exercise behaviour (see table 2 and 3). With regard to physical activity only the tension/pressure subscale of the IMI significantly contributed to the prediction of physical activity levels.

Table 2

Hierarchical multiple regression change analysis for the group as a whole $(N=226)$ and for the males $(N=90)$ and females $(N=136)$ separately for exercise and physical activity patterns. Step one: SMI: Step two: 4 subscales IMI; Step three: four body composition measurements; Step four: gender.

\begin{tabular}{|c|c|c|c|c|c|c|}
\hline \multicolumn{7}{|c|}{ Exercise } \\
\hline & \multicolumn{2}{|c|}{ All participants } & \multicolumn{2}{|c|}{ Males } & \multicolumn{2}{|l|}{ Females } \\
\hline & $\begin{array}{l}\text { Significance } \\
F \text { change }\end{array}$ & $R^{2}$ & $\begin{array}{l}\text { Significance } \\
F \text { change }\end{array}$ & $R^{2}$ & $\begin{array}{l}\text { Significance } \\
F \text { change }\end{array}$ & $R^{2}$ \\
\hline Step 1 & 0.001 & 0.051 & 0.010 & 0.074 & 0.019 & 0.041 \\
\hline Step 2 & 0.257 & 0.074 & 0.779 & 0.093 & 0.019 & 0.123 \\
\hline Step 3 & 0.001 & 0.141 & 0.446 & 0.133 & 0.057 & 0.184 \\
\hline Step 4 & 0.621 & 0.142 & & & & \\
\hline \multicolumn{7}{|c|}{ Physical Activity } \\
\hline & \multicolumn{2}{|c|}{ All participants } & \multicolumn{2}{|c|}{ Males } & \multicolumn{2}{|l|}{ Females } \\
\hline & $\begin{array}{l}\text { Significance } \\
F \text { change }\end{array}$ & $R^{2}$ & $\begin{array}{l}\text { Significance } \\
F \text { change }\end{array}$ & $R^{2}$ & $\begin{array}{l}\text { Significance } \\
\text { F change }\end{array}$ & $R^{2}$ \\
\hline Step 1 & 0.086 & 0.000 & 0.568 & 0.004 & 0.878 & 0.000 \\
\hline Step 2 & 0.029 & 0.048 & 0.920 & 0.011 & 0.008 & 0.099 \\
\hline Step 3 & 0.613 & 0.060 & 0.988 & 0.004 & 0.393 & 0.128 \\
\hline Step 4 & 0.093 & 0.072 & & & & \\
\hline
\end{tabular}




Table 3

Significance and beta value of the dependent variables for the best hierarchical multiple regression model for the group as a whole $(N=226)$ and for the males $(N=90)$ and females $(N=136)$ separately for exercise and physical activity patterns.

\begin{tabular}{|c|c|c|c|c|c|c|}
\hline \multicolumn{7}{|c|}{ Exercise } \\
\hline & \multicolumn{2}{|c|}{ All Participants } & \multicolumn{2}{|c|}{ Males } & \multicolumn{2}{|c|}{ Females } \\
\hline & Beta & Sig & Beta & Sig & Beta & Sig \\
\hline SMI & 0.215 & 0.001 & 0.272 & 0.010 & 0.114 & 0.193 \\
\hline $\begin{array}{l}\text { Interest/ } \\
\text { Enjoyment }\end{array}$ & -0.014 & 0.851 & & & 0.130 & 0.174 \\
\hline $\begin{array}{l}\text { Perceived } \\
\text { Competence }\end{array}$ & 0.066 & 0.348 & & & 0.078 & 0.412 \\
\hline $\begin{array}{l}\text { Effort/ } \\
\text { Importance }\end{array}$ & 0.040 & 0.568 & & & 0.034 & 0.722 \\
\hline $\begin{array}{l}\text { Tension/ } \\
\text { Pressure }\end{array}$ & -0.099 & 0.136 & & & -0.132 & 0.141 \\
\hline Body weight & 0.401 & 0.006 & & & 0.520 & 0.003 \\
\hline $\begin{array}{l}\text { Percentage } \\
\text { Body fat }\end{array}$ & -0.202 & 0.028 & & & -0.072 & 0.534 \\
\hline BMI & -0.117 & 0.478 & & & -0.399 & 0.018 \\
\hline WHR & -0.010 & 0.893 & & & -0.035 & 0.689 \\
\hline \multicolumn{7}{|c|}{ Physical Activity } \\
\hline & \multicolumn{2}{|c|}{ All Participants } & \multicolumn{2}{|c|}{ Males } & \multicolumn{2}{|c|}{ Females } \\
\hline & Beta & Sig & Beta & Sig & Beta & Sig \\
\hline SMI & -0.010 & 0.880 & & & -0.027 & 0.809 \\
\hline $\begin{array}{l}\text { Interest/ } \\
\text { Enjoyment }\end{array}$ & 0.027 & 0.723 & & & 0.009 & 0.928 \\
\hline $\begin{array}{l}\text { Perceived } \\
\text { Competence }\end{array}$ & 0.085 & 0.242 & & & 0.124 & 0.205 \\
\hline $\begin{array}{l}\text { Effort/ } \\
\text { Importance }\end{array}$ & 0.059 & 0.417 & & & 0.091 & 0.356 \\
\hline $\begin{array}{l}\text { Tension/ } \\
\text { Pressure }\end{array}$ & -0.190 & 0.005 & & & -0.276 & 0.002 \\
\hline
\end{tabular}


Remco Polman, Willy Pieter, Luigi T. Bercades, \& Nikos Ntoumanis

The hierarchical multiple regression for the males, however, only found that self-motivation predicted exercise behaviour whereas none of the dependent variables predicted physical activity levels. For the females, on the other hand, exercise was predicted by body weight and $\mathrm{BMI}$ whereas physical activity levels was predicted by the tension/pressure subscale of the IMI.

Finally, Pearson coefficient correlations did not show inverse relationships between the body composition measurements and physical activity and exercise for the males. With regard to the females, only a small significant positive correlation was found between body weight and exercise $(r=0.19)$ indicating that an increase in physical exercise was associated with an increase in body weight for the females.

\section{Discussion}

The male participants in the present study exhibited, as expected, significantly higher levels of exercise and the females significantly higher physical activity levels. When physical activity and exercise levels were pooled together males had significantly higher total activity patterns in comparison to the females. This finding is in agreement with those obtained in a similar US population - male students being more vigorously active in comparison to their female counterparts (Pratt, Macera, \& Blanton, 1999). The present study's results suggest that these observations are independent of culture and/or ethnicity. There is a multitude of reasons for these differences in exercise levels of males and females. With regard to the Filipino population under investigation, it might be argued that the existence of traditional gender roles might impede females to take part in vigorous exercise (Johnson, 2000). This could be due to a lack of sporting opportunities for women, including lack of women only sports clubs. The gender differences in exercise and physical activity levels suggest, however, that both physical activity and exercise levels have to be taken into account when investigating physical activity/ exercise behaviour of populations. In principle all forms of energy expenditure can influence body composition and health. This could be achieved through a generally more active lifestyle as well as through vigorous exercise (Haskell, 1994).

The present study also found that the general measure of self-motivation together with body weight and percentage body fat were the best predictors of exercise behaviour for the group as a whole thereby supporting the psychobiological approach. However, there were some important gender differences. For the males, only self-motivation and for the females body weight and BMI predicted exercise behaviour. The finding that males showed higher levels of exercise behaviour and that these were best predicted by selfmotivation would support the assertion put forward by Biddle and Mutrie (2001). They suggested that activities that are of high intensity (higher metabolic demands) require higher levels of self-motivation and a favourable body composition in order for participants to maintain these behaviours. Although the present study did not find any of the body composition measures significantly contributing to the model for the males, percentage of body fat did, however, approach significance $(p=0.066)$. For the females, on the other hand, higher levels of exercise were associated with increased body weight. Several cross-sectional population-based comparisons have, however, indicated that an




inverse relationship exists between body weight and self-reported exercise and/or physical activity levels (Ballor \& Keesey, 1991; French et al., 1994). A possible explanation for this finding might be the types of activities the females mainly participated in - swimming, tennis, and soccer - and environmental factors. Firstly, group or racket sports do not result in considerable weight changes depending on intensity, duration, and frequency of exercise (French et al., 1994). Secondly, environmental factors have been shown to influence reported participation in exercise (Pratt et al., 1999). That is, a hot and humid climate prevents people from exercising vigorously. In Metro Manila the weather is not only hot and humid but is also accompanied by high pollution levels making vigorous exercise even more uncomfortable. Thirdly, the participants in this study were from a relatively affluent background, many of them adopting a western lifestyle, which is accompanied by consumption of relatively high fat/energy food. In general, a decrease in body weight (mostly fat weight) is only seen when exercise sessions are of long duration and high in intensity (DiPietro, Williamson, Caspersen, \& Eaker, 1993). Fourthly, it has been shown that people have the tendency to over report their levels of exercise (ADNFS, 1992). Thus, type of activities, environmental factors, and lifestyle resulting in relatively low energy expenditure when exercising, a relatively high caloric intake, and the over reporting of exercise levels might explain the positive association between body weight and exercise for the Filipino females in this study.

A possible limitation of the present study was that only levels of intrinsic motivation were assessed. However, it is believed that the intrinsic motives are most likely to result in positive behavioural as well as affective outcomes (for example enjoyment and competence) and are therefore critical for sustained physical activity and exercise (Ryan et al., 1997; Vallerand, 2001). Extrinsic motives, on the other hand, have been viewed as an important trigger for the adoption of exercise (Ryan et al.). The results of the present study only found that the tension/pressure subscale of the IMI was a predictor of levels of physical activity for the group as a whole and the females separately but not for the males. In this respect, the psychological effects of physical activity and exercise are well documented - participation in regular physical activity and exercise being associated with a decrease in anxiety and depression and an increase in general mood (Biddle et al., 2000). The lower levels in tension/pressure associated with higher levels of physical activity would support this notion. The differences found between the genders in physical activity levels could be one explanation why the tension/pressure subscale was a predictor for the females but not the males. It could be suggested that a threshold level of physical activity has to be attained in order to gain these psychological benefits from physical activity. Or, on the other hand, for females these activities are more likely to be perceived as a break from daily hassles in comparison to the males (Bahrke \& Morgan, 1978).

Interestingly, the scores obtained on the SMI for this study appeared to be fairly low in comparison with scores obtained in other studies. Analysis of weighted means with unequal sample size was conducted to compare the SMI scores for the present Filipino sample with those obtained in 9 studies conducted in western societies (see table 4). This analysis yielded a highly significant main effect, $F(9,1310)=34.78, p<0.001$. Post-hoc comparisons showed that the SMI scores of the present study were significantly lower than those found in any of the other studies $(p<0.05)$. 
Remco Polman, Willy Pieter, Luigi T. Bercades, \& Nikos Ntoumanis

Table 4

Means, standard deviations, and number of subjects of studies which have used the SMI.

\begin{tabular}{lccc}
\multicolumn{1}{c}{ Study } & Mean & SD & N \\
\hline Dishman et al. (1980) & 140.5 & 19.4 & 399 \\
Dishman \& Gettman (1980) & 153.5 & 19.9 & 66 \\
Freedson et al. (1983) & 157.6 & 10.5 & 8 \\
Garcia \& King (1991) & 146.7 & 20.1 & 74 \\
Heiby et al. (1987) & 145.2 & 23.4 & 220 \\
Murphy et al. (1998) & 141.4 & 14.1 & 38 \\
Raglin et al. (1990) & 154.6 & 12.9 & 84 \\
Robertson \& Mutrie (1989) & 131.6 & 14.6 & 80 \\
Ward \& Morgan (1984) & 141.4 & 18.6 & 76 \\
Present study & 109.4 & 16.4 & 226
\end{tabular}

There is no doubt that there is a growing need to understand cultural variations in exercise and physical activity behaviour. Factors influencing such behaviours might be affected by ethnicity and/or cultural differences. Considering the above findings, differences in motivational orientation have been reported elsewhere in the literature. For example, Li, Harmer, Chi, and Vongiaturapat (1996) found that goal orientations varied as a result of culture in their Thai sample. In this study, a positive relationship between task and ego orientation was found, whereas no relationship would be expected in a Caucasian sample (Duda \& Nicholls, 1992). Kim (1995) has obtained a similar result in a Korean population. Although self-motivation scores were related to the participants exercise levels further research should establish if the SMI would be a valid scale to be used in societies with different ethnic/cultural orientations. In order to do this, its functional, conceptual, and/or psychometric equivalence have to be reassessed (Duda \& Hayashi, 1998).

The lack of inverse relationships between the selected body composition measures and exercise and physical activity levels was unexpected. It has been suggested, however, that physical activity and exercise have less of an influence on body composition during younger age. Older people might benefit more from exercise and physical activity because of the decline in muscle-to-fat ratio with age (DiPietro, 1995; DiPietro et al., 1993). Such an argument might explain the lack of association between body composition measures and exercise and physical activity behaviours. An additional issue is that the use of questionnaires,

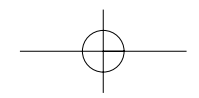


although the most practical method for assessing energy expenditure, has some major limitation; the validity and reliability, for example, are generally only moderate (see Melby, Ho, \& Hill, 2000 for an overview). Another important issue has been the lack of data in the scientific literature on non-Caucasian populations. For example, the calculation of body fat percentage in this study was based on a formula derived from a sample of Japanese. No normative data are available for Filipinos. This void in the scientific literature is unfortunate and more effort is required to establish criteria for people from different ethnic origin.

In conclusion, the psychobiological model was valid when predicting exercise behaviour for the group as a whole. That is, self-motivation, body weight, and percentage body fat being the best predictors of the participants level of exercise behaviour. However, there were some significant gender differences for the population under investigation. Self-motivation was a strong predictor for exercise behaviour for the males whereas body weight and BMI were predictors for the females. Physical activity behaviour, on the other hand, was best predicted by the tension/ pressure subscale of the IMI for the group as a whole and for the females but not the males. This would suggest that the general first order personality trait of self-motivation was better in predicting exercise behaviour, particularly for males and when executed at higher levels. The latter could be achieved by exercising more frequently, for longer duration, or at higher intensities. Self-motivation, in this respect, seems to be more important for activities that do not result in immediate reinforcement (Dishman \& Ickes, 1981). The tension/pressure subscale of the IMI was best in predicting physical activity behaviour, in particular that of the females. The data of the present study suggest that the psychobiological model might be more relevant when dealing with participants who exercise at relatively high levels. Low levels of selfmotivation and possible unfavourable body composition (high fat percentage) being indicators of possible dropout. An important implication of the findings of the present study would be to treat males and females differently when designing exercise and/or physical activity intervention programs. Interventions for the males, for example, could be designed and targeted to those participants low in self-motivation in particular when the activity is not likely to be intrinsically enjoyable and of high intensity, duration, and/or frequency. For the females, on the other hand, the selection of activities and the commitment and/or involvement would be important issues to monitor. Finally, there is a need for further research into the relationship between exercise and physical activity and body composition in different cultures. Ultimately, these are related to health issues. For example, the epidemiological increase of diabetes mellitus in the Asia-Pacific region has been attributed to changes in lifestyle. In particular, changes in dietary habits and exercise and physical activity have been found to be associated with the development of (central) obesity in younger individuals in the Asian-Pacific region (Cockram, 2000). These issues are particularly important for the relatively affluent student population in the present study. 
Remco Polman, Willy Pieter, Luigi T. Bercades, \& Nikos Ntoumanis

\section{REFERENCES}

Allied Dunbar National Fitness Survey (1992). Main findings. London: Sports Council \& Health Education Authority.

Annesi, J.J. (2002). Self-motivation moderates effect of exercise-induced feelings on adherence. Perceptual and Motor Skills, 94, 467-475.

Bahrke, M.S., \& Morgan, W.P. (1978). Anxiety reduction following exercise and meditation. Cognitive Therapy and Research, 2, 323-334.

Ballor, D. L., \& Keesey, R. E. (1991). A meta-analysis of the factors affecting exercise induced changes in body mass, fat mass, and fat-free mass in males and females. International Journal of Obesity, 5, 717-726.

Berger, B.G., Pargman, D., \& Weinberg, R.S. (2002). Foundations of exercise psychology. Morgantown, WV: Fitness Information Technology.

Biddle, S.J.H., \& Mutrie, N. (2001). Psychology of physical activity: Determinants, well-being, and interventions. London: Routledge.

Biddle, S. J. H., Fox, K. R., \& Boutcher, S. H. (2000). Physical activity and psychological wellbeing. London: Routledge.

Biddle, S. J. H., Soos, I., \& Chatzisarantis, N. L. D. (1999). Predicting physical activity intentions using a goal perspective approach: A study of Hungarian youth. Scandinavian Journal of Medicine and Science in Sport, 9, 353-357.

Chatzisarantis, N. L. D., Biddle, S. J. H., \& Meek, G. A. (1997). A self-determination theory approach to the study of intentions and the intention-behaviour relationship in children's physical activity. British Journal of Health Psychology, 2, 343-360.

Cockram, C. S. (2000). The empidemiology of diabetes mellitus in the Asian-Pacific region. Hong Kong Medical Journal, 6, 43-52.

Cronbach, L.J. (1951). Coefficient alpha and the internal structure of tests. Psychometrika, 16, 296-334.

Deci, E. L., \& Ryan, R. M. (1985). Intrinsic motivation and self-determination in human behaviour. New York: Plenum Press.

DiPietro, L. (1995). Physical activity, body weight, and adiposity: An epidemiologic perspective. Exercise and Sport Science Reviews, 23, 275-303.

DiPietro, L., Williamson, D. F., Caspersen, C. J., \& Eaker, E. (1993). The descriptive epidemiology of selected physical activities and body weight among adults trying to lose weight: The behavioural risk factor surveillance system survey, 1989. International Journal of Obesity, 17, 69-76.

Dishman, R.K. (2001). The problem of exercise adherence: Fighting sloth in nations with market economies. Quest, 53, 279-294.

Dishman, R. K., \& Gettman, L. R. (1980). Psychobiologic influences on exercise adherence. Journal of Sport Psychology, 2, 295-310.

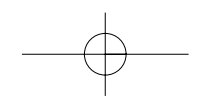


Dishman, R. K., \& Ickes, W. (1981). Self-motivation and adherence to therapeutic exercise. Journal of Behavioral Medicine, 4, 421-438.

Dishman, R.K., \& Steinhardt, M. (1988). Reliability and concurrent validity for a seven-day recall of physical activity in college students. Medicine and Science in Sports and Exercise, 20, 14-25.

Dishman, R. K., Ickes, W., \& Morgan, W. P. (1980). Self-motivation and adherence to habitual physical activity. Journal of Apllied Social Psychology, 10, 115-132.

Duda, J. L., \& Hayashi, C. T. (1998). Measurement issues in cross-cultural research within sport and exercise psychology. In J. L. Duda (Ed.), Advances in sport and exercise psychology measurement (pp. 471-483). Morgantown: Fitness Information Technology.

Duda, J. L., \& Nicholls, J. (1992). Dimensions of achievement motivation in schoolwork and sport. Journal of Educational Psychology, 84, 290-299.

Duncan, J. J., Gordon, N. F., \& Scott, C. B. (1991). Women walking for health and fitness. How much is enough? Journal of the Amarican Medical Association, 266, 3295-3299.

Frederick, C. M., \& Ryan, R. M. (1993). Differences in motivation for sport and exercise and their relationship with participation and mental health. Journal of Sport Behavior, 16, 125 145.

Freedson, P.S., Mihevic, P.M., Loucks, A.B., \& Girandola, R.N. (1983). Physique, body composition, and psychological characteristics of competitive female body builders. The Physician and Sportsmedicine, 11, 85-93.

French, S. A., Jeffery, R. W., Forster, J. L., McGovern, P. G., Kelder, S. H., \& Baxter, J. E. (1994). Predictors of weight change over two years among a population of working adults: The healthy worker project. International Journal of Obesity, 18, 145-154.

Garcia, A. W., \& King, A. C. (1991). Predicting long-term adherence to aerobic exercise: A comparison of two models. Journal of Sport and Exercise Psychology, 13, 394-410.

Haskell, W. L. (1994). Health consequences of physical activity: Understanding and challenges regarding dose-response. Medicine and Science in Sport, 26, 649-660.

Heiby, E. M., Onorator, V. A., \& Sato, R. A. (1987). Cross-validation of the self-motivation inventory. Journal of Sport Psychology, 9, 394-399.

Heyward, V.H., \& Stolarczyk, L.M. (1996). Applied body composition assessment. Champaign, IL: Human Kinetics.

Johnson, M. R. D. (2000). Perceptions of barriers to healthy physical activity among Asian communities. Sport, Education and Society, 5, 51-70.

Kim, B. J. (1995). Psychometric evaluation of the TEOSQ and the IMI in a Korean sport setting. Journal of Sport and Exercise Psychology, 17, S66.

King, A. C., Blair, S. N., Bild, D. E., Dishman, R. K., Dubbert, P. M., Marcus, B. H., Oldrige, N. B., Paffenbarger, R. S., Powell, K. E., \& Yeager, K. K. (1992). Determinants of physical activity and interventions in adults. Medicine and Science in Sport and Exercise, 24, S221S236. 
Remco Polman, Willy Pieter, Luigi T. Bercades, \& Nikos Ntoumanis

Li, F., Harmer, P., Chi, L., \& Vongiaturapat, N. (1996). Cross-cultural validation of the Task and Ego Orientation in Sport Questionnaire. Journal of Sport and Exercise Psychology, 18, 392407.

Lohman, T.G. (1981). Skinfolds and body density and their relation to body fatness: A review. Human Biology, 53, 181-225.

Massie, J. F., \& Sheppard, R. J. (1971). Physiological and psychological effects of training. Medicine and Science in Sport, 3, 110-117.

McAuley, E., Duncan, T. E., \& Tammen, V. V. (1989). Psychometric properties of the Intrinsic Motivation Inventory in a competitive sport setting: A confirmatory factor analysis. Research Quarterly for Exercise and Sport, 60, 48-58.

Melby, C.L., Ho., R.C., \& Hill. J.O. (2000). Assessment of human energy expenditure. In C. Bouchard (Ed.), Physical activity and obesity. Champaign, IL: Human kinetics.

Montoye, H. J., Kemper, H. C. G., Saris, W. H. M., \& Washburn, R. A. (1996). Measuring physical activity and energy expenditure. Champaign, IL: Human Kinetics.

Murphy, C. S., Polman, R. C. J., \& Pieter, W. (1998). Attitudes to physical activity and motivation for exercise adherence using a health-related fitness program. In, Australian Conference of Science and Medicine in Sport Abstract Book (p. 199). Canberra: Sports Medicine Australia.

Ntoumanis, N. (2001). A self-determination approach to the understanding of motivation in physical education. British Journal of Educational Psychology, 71, 225-242.

Pratt, M., Macera, C. A., \& Blanton, C. (1999). Levels of physical activity and inactivity in children and adults in the United States: Current evidence and research issues. Medicine and Science in Sport, 31, S526-S533.

Raglin, J.S., Morgan, W.P., \& Luchsinger, A.E. (1990). Mood and self-motivation in successful and unsuccessful female rowers. Medicine and Science in Sports and Exercise, 22, 849853.

Robertson, J., \& Mutrie, N. (1989). Factors in adherence to exercise. Physical Education Review, 23, 138-146.

Ryan, R. M., Frederick, C. M., Lepes, D., Rubio, N., \& Sheldon, K. (1997). Intrinsic motivation and exercise adherence. International Journal of Sport Psychology, 28, 335-354.

Sallis, J. F., \& Owen, N. (1999). Physical activity and behavioural medicine. London: Sage.

Schoenborn, C. A. (1986). Health habits of U.S. adults: The 'Alameda 7' revisited. Public Health Reports, 101, 571-580.

Selby, J. V., Newman, B., \& Quesenberry, C. (1990). Genetic and behavioural influences on body fat distribution. International Journal of Obesity, 14, 593-602.

Siedell, J. C., Biorntorp, P., \& Sjostrom, L. (1989). Regional distribution of fat in men: New insight into the risk of abdominal obesity using computed tomography. International Journal of Obesity, 13, 289-303.

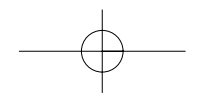


Silberstein, L., Striegel-Moore, R., Timko, C., \& Rodin, J. (1988). Behavioural and psychological implications of body dissatisfaction: Do men and women differ? Sex Roles, 19, 219-232.

Stephens, T., Jacobs, D. R. J., \& White, C. C. (1985). A descriptive epidemiology of leisure time physical activity. Public Health Reports, 100, 147-158.

Steinhardt, M.A., \& Young, D.R. (1992). Psychological attributes of participants and nonparticipants in a worksite health and fitness centre. Behavioral Medicine, 18, 40-46.

Tappe, M. K., Duda, J. L., \& Menges-Ehrnwald, P. (1990). Personal investment predictors of adolescent motivational orientations toward exercise. Canadian Journal of Sport Sciences, $15,185-192$.

Tsunenari, T., Tsutsumi, M., Ohno, K., Yamamoto, Y., Kawakutsu, M., Shimogaki, K., Negishi, H., Sugimoto, T., Fukase, M., \& Fujita, T. (1993). Age- and gender-related changes in body composition in Japanese subjects. Journal of Bone and Mineral Research, 8, 397-402.

U.S. Department of Health and Human Services (2000). Healthy people 2010. Washington, DC: US Government Printing Office.

U.S. Department of Health and Human Services (1996). Physical activity and health: A report of the Surgeon General. Atlanta, GA: Centres for Disease Control.

Vallerand, R. J. (2001). A hierarchical model of intrinsic and extrinsic motivation in sport and exercise. In G. C. Roberts (Ed.), Advances in motivation in sport and exercise (pp. 263319). Champaign, IL: Human Kinetics.

Vallerand, R. J., \& Fortier, M. S. (1998). Measures of intrinsic and extrinsic motivation in sport and physical activity: A review and critique. In J. L. Duda (Ed.), Advances in sport and exercise psychology measurement. Morgantown: Fitness Information Technology.

Vallerand, R. J., Pelletier, L. G., Blais, M. R., Briere, N. M., Senecal, C., \& Vallieres, E. F. (1992). The academic motivation scale: A measurement of intrinsic, extrinsic and amotivation in education. Educational and Psychological Measurement, 52, 1003-1019.

Ward, A., \& Morgan, W. P. (1984). Adherence patterns of healthy men and women enrolled in an adult exercise program. Journal of Cardiac Rehabilitation, 4, 143-152.

Wilcox, S., \& Storandt, M. (1996). Relations among age, exercise, and psychological variables in a community sample of women. Health Psychology, 15, 110-113.

Wilfley, D. E., \& Browell, K. D. (1994). Physical activity and diet in weight loss. In R. K. Dishman (Ed.), Advances in exercise adherence. Champaign, IL: Human Kinetics. 